\title{
Composição funcional e sazonalidade da macrofauna edáfica em diferentes usos do solo, Bioma Cerrado, Brasil
}

\begin{abstract}
A macrofauna edáfica é representada por organismos invertebrados que ocupam o solo e podem ser distribuídos em grupos funcionais que desempenham funções especificas nos ambientes. Este trabalho objetivou-se analisar a composição funcional da macrofauna edáfica e sazonalidade em diferentes usos do solo, do bioma Cerrado. A pesquisa foi realizada em ambientes que reúnem características naturais (Cerradão e Mata dos Cocais) e formações florestais que sofreram perturbações antrópicas (Corte e Queima, Eucalipto e Pastagem), em Chapadinha, Maranhão, Brasil. Os invertebrados edáficos foram coletados no período chuvoso e no período seco, e identificados em nível de ordem e/ou família. Foram coletados 2149 indivíduos da macrofauna edáfica, pertencentes a 16 grupos taxonômicos, distribuídos em cinco grupos funcionais: engenheiros dos ecossistemas, saprófagos, predadores, onívoros e fitófagos; sendo que os predadores reuniram o maior número de táxons. Foi calculada a beta diversidade da macrofauna edáfica particionada em substituição (betasim) e aninhamento (betasne) tanto em ambientes naturais como antrópicos. Observou-se que todos os valores de substituição foram maiores que os valores de aninhamento em todos os ambientes e períodos. $\mathrm{O}$ teste da PERMANOVA verificou alterações significativas na composição dos grupos funcionais da macrofauna edáfica para a interação dos fatores: período sazonal e ambiente. Foi observado sobreposição entre ambientes quanto nos eixos 1 e 2 do NMDS envolvendo os cinco grupos funcionais. Conclui-se que os grupos funcionais da macrofauna edáfica (engenheiros dos ecossistemas, saprófagos, predadores, onívoros, fitófagos) desempenham atividades que regulam muitos processos físicos, químico e biológicos que ocorrem no solo do bioma Cerrado, além de promover o seu equilíbrio e o funcionamento habitual.
\end{abstract}

Palavras-chave: Invertebrados; Funcionalidade; Hábito alimentar; Paisagem.

\section{Functional composition and seasonalityins of soil macrofauna in different soil uses, Cerrado Biome, Brazil}

\begin{abstract}
The edaphic macrofauna is represented by invertebrate organisms that occupy the soil and can be distributed in functional groups that realize specific functions in the environments. The objective of this study was to analyze the functional composition of the edaphic macrofauna and seasonalityins of the Cerrado biome in different uses of the soil. The research was carried out in environments that combine natural characteristics (Cerradão and Mata dos Cocais) and forest formations that suffered anthropic disturbances (Cut and Burn, Eucalyptus and Pasture), in Chapadinha, Brazil. The edaphic invertebrates were collected in the rainy period and in the dry period, and identified at the level of order and/or family. Was found 2149 individuals from the edaphic macrofauna, belonging to 16 taxonomic groups, distributed in five functional groups: ecosystem engineers, saprophages, predators, omnivores and phytophages; predators gathered the largest number of táxons. Was observed the beta diversity of the edaphic macrofauna partitioned in substitution (betasim) and nesting (betasne) as in natural as anthropic environments. Observed that all substitution values were greater than nesting values in all environments and periods. The PERMANOVA test found significant changes in the composition of the functional groups of the edaphic macrofauna for the interaction of the factors: seasonal period and environment. Superposition was observed between environments and in axes 1 and 2 of the NMDS involving the five functional groups. It is concluded that the functional groups of the edaphic macrofauna (ecosystem engineers, saprophages, predators, omnivores, phytophages) perform activities that regulate many physical, chemical and biological processes that occur in the soil of the Cerrado biome, in addition to promoting their balance and usual operation.
\end{abstract}

Keywords: Invertebrates; Functionality; Food habit; Landscape.

Topic: Ciências do Solo

Reviewed anonymously in the process of blind peer.

Charlyan de Sousa Lima (iD

Universidade do Vale do Taquari, Brasil

http://lattes.cnpq.br/1033417364789024

http://orcid.org/0000-0002-6100-0325

charlyansl@yahoo.com.br

Marina Schmidt Dalzochio

Universidade do Vale do Taquari, Brasil

http://lattes.cnpq.br/8400882066099257

http://orcid.org/0000-0001-9241-921X

mahsdalzochio@gmail.com

Edison Fernandes da Silva (ib

Universidade Federal do Maranhão, Brasil

http://lattes.cnpq.br/3962858158135882

http://orcid.org/0000-0002-2195-0051

edibocaiuva@yahoo.com.br

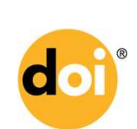

DOI: 10.6008/CBPC2179-6858.2020.006.0004
Received: 02/10/2020

Approved: 20/11/2020
Eduardo Périco (iD

Universidade de São Paulo, Brasil

http://lattes.cnpq.br/4494244221645524

http://orcid.org/0000-0002-2926-6246

perico@univates.br
Referencing this:

LIMA, C. S.; DALZOCHIO, M. S.; SILVA, E. F.; PÉRICO, E.. Composição funcional e sazonalidade da macrofauna edáfica em diferentes usos do solo, Bioma Cerrado, Brasil. Revista Ibero Americana de Ciências Ambientais, v.11, n.6, p.33-48, 2020. DOI: http://doi.org/10.6008/CBPC2179-6858.2020.006.0004 


\section{INTRODUÇÃO}

A macrofauna edáfica é representada por organismos invertebrados que ocupam a superfície do solo e desempenham funções especificas. Para realizar suas atividades no solo, os táxons que a compõem podem ser distribuídos em grupos funcionais, que incluem: engenheiros dos ecossistemas, saprófagos, predadores, onívoros e fitófagos (ELIEA et al., 2018; FERREIRA et al., 2019).

Os engenheiros dos ecossistemas (EDE), causam impacto especifico no solo, transformando suas propriedades físicas que melhoram a movimentação e retenção de água e trocas gasosas, além de formarem agregados que constituirão a estrutura interna do solo (PERKINS et al., 2018; ZHANG et al., 2018). Esse grupo tem sua atividade tanto na superfície como no interior do solo, podendo inclusive auxiliar outros grupos funcionais no desempenho de atividades. Podem auxiliar na remoção da serapilheira ajudando os invertebrados onívoros a fragmentar a estrutura vegetal, e ao mesmo tempo, propiciam aos saprófagos a decomposição da matéria orgânica no solo (NUNES et al., 2019; MURPHY et al., 2020). Os EDE podem ser representados por formigas (Hymenoptera: Formicidae), minhocas (Haplotaxida), cupins (Isoptera), dentre outros invertebrados edáficos.

Os saprófagos (Blattodea, Diplopoda, Diplura, Psocoptera, etc.) atuam na decomposição da matéria orgânica melhorando a química e a fertilidade do solo. O material decomposto passa a ser incorporado ao solo, fornecendo nutrientes como nitrogênio, fósforo, potássio e dentre outros, que previamente serão utilizados pelas plantas por meio do processo da seiva bruta, quando esses nutrientes são absorvidos pelas raízes e direcionados a outros órgãos vegetais (PEÑA-PEÑA et al., 2016; FROUZ, 2017). Assim os saprófagos participam indiretamente da fisiologia vegetal, o que condicionará melhores condições de sobrevivência tanto para flora e fauna de um determinado ambiente.

Os predadores é um grupo funcional que pode participar de diferentes níveis tróficos da cadeia alimentar, desempenhando função de controle populacional nos ecossistemas terrestres. Os principais representantes são os aracnídeos (Araneae, Pseudoscorpionida) e centopeias (Scolopendromorpha) (MURPHY et al., 2020). Já os onívoros (Blattaria, Coleoptera e outros) também podem participar de muitos níveis tróficos, consumindo organismo vegetal e animal, tornando-se um grupo abundante na natureza, que atua no solo nos processos de regulação dos invertebrados edáficos e da constituição da serapilheira (KULKARNIA et al., 2017).

Quanto aos fitófagos (Orthoptera, Hemiptera, etc.) são invertebrados que tanto anatomicamente como fisiologicamente estão adaptados para o consumo de matéria vegetal, tornando-se o principal componente de sua dieta. Desse modo, podem participar de diversas atividades que ocorrem na superfície do solo, nutrindo-se de fragmentos vegetais presentes na serapilheira. Além disso, sua abundância e riqueza pode ser determinada pela composição vegetacional do ambiente, desempenhando também papel no equilíbrio ecológico, por meio de sua participação na cadeia alimentar (ANDREW et al., 2005).

O bioma Cerrado é rico em diversidade de organismos edáficos, e um importante hotspot, embora sofra ameaças antrópicas, devido à exploração excessiva de seus recursos naturais, afetando 
consideravelmente a fitofisionomia e alterando negativamente a química e a fertilidade dos solos (LIMA et al., 2020).

Esse trabalho teve como objetivo analisar a composição funcional da macrofauna edáfica e sua sazonalidade, guiados pelas seguintes hipóteses: 1) os organismos representantes das diferentes categorias funcionais variam conforme a fitofisionomia e sazonalidade, 2) áreas com forte influência antrópica apresentam grupos funcionais mais generalistas que áreas naturais.

\section{METODOLOGIA}

A pesquisa foi conduzida em cinco ambientes do bioma Cerrado, município de Chapadinha (344'31" S e 4321'36" W), Estado do Maranhão, Brasil. Segundo a classificação de Köppen o clima é do tipo tropical quente e úmido (Aw), com temperatura média anual superior a 27 C e precipitação pluvial média anual de $1.835 \mathrm{~mm}$, com sazonalidade distribuída em períodos: chuvoso (entre os meses de janeiro e junho) e seco (entre os meses de julho a dezembro), tendo a umidade relativa do ar anual correspondente entre 73 e $79 \%$ (IBGE, 2016). Os ambientes selecionados reúnem características naturais (Cerradão e Mata dos Cocais) e formações florestais que sofreram perturbações antrópicas (Corte e Queima, Eucalipto e Pastagem). Esses ambientes exibem as seguintes características: - Cerradão (03S 42'12,9" e 43N 20'12,9'): formação vegetal florestada, tipo Cerradão, com árvores de pequeno e médio porte que podem atingir de 10 a $15 \mathrm{~m}$ de altura. Sua característica estrutural é arbórea, xeromórfica, espécies com grandes folhas coriáceas e perenes, casca corticosa e sem estrato arbustivo nítido; - Mata dos Cocais (03S 43'08,7" S e 43N 23' 06,9"): vegetação constituída principalmente por palmeira babaçu Attalea speciosa Mart. Ex Spreng (1826); - Corte e Queima (03S 42' 22,4" e 43N 22' 41,0"): área de agricultura tradicional de subsistência (milho, feijão e mandioca), sem adubação e sem calagem, com capinas manuais periódicos; - Eucalipto (03S 44'02,2" S e 43N 17'23,4"): representado por área plantada com a cultura do eucalipto (Eucalyptus sp.); - Pastagem (03S 51'06,5" e 43N 19'06,3"): área dominada por vegetação herbácea espécie Andropogon gayanus Kunth (1833) usada para pecuária semi intensiva.

Para cada ambiente foi escolhido uma área com dimensão 240 × 160 m, e posicionados três transectos de $80 \mathrm{~m}$, equidistantes a $80 \mathrm{~m}$. Foram colocadas cinco armadilhas pitfall com distância de $20 \mathrm{~m}$ entre si, em cada transecto, respondendo a 15 armadilhas em cada ambiente de estudo. Cada armadilha (pitfall trap) foi constituída de um recipiente plástico cilíndrico, com $9 \mathrm{~cm}$ de diâmetro e $10 \mathrm{~cm}$ de altura, onde a borda ficou ao nível do solo, com $200 \mathrm{~mL}$ de formol a 4\% como solução conservante.

As coletas da macrofauna edáfica ocorreram no período chuvoso (mês de abril) e no período seco (mês de outubro). Durante sete dias as armadilhas permaneceram no campo. Após esse período, procedeuse a retirada dos invertebrados edáficos, que foram armazenados em recipientes com álcool a $70 \%$, e encaminhados ao laboratório para triagem e identificação dos grupos taxonômicos a nível de subclasse, ordem e/ou família, de acordo com Rafael (2012).

Foi realizada análise qualitativa da comunidade da macrofauna edáfica distribuindo os grupos taxonômicos em cinco grupos funcionais de acordo com o uso do habitat e os recursos alimentares segundo 
Brown et al. (2001) e Swift et al. (2010).

Para análise da beta diversidade foi utilizado o programa estatístico R, pacote betapart, função beta.multi. O Modelo Linear Generalizado (GLM) foi utilizado para comparar a abundância dos grupos funcionais e riqueza, entre o período e as áreas, com auxílio do software $R$ utilizando os pacotes MASS (função glm.nb) e Ime4 (função glm). A distribuição dos dados foi testada com o pacote fitdistrplus (função descdist) também do software $R$.

Foi realizado a Análise de Variância Multivariada Permutacional (PERMANOVA) para testar as diferenças na composição dos grupos funcionais da macrofauna edáfica, considerando os cinco ambientes (cerradão, mata dos cocais, corte e queima, eucalipto e pastagem) e os dois períodos (chuvoso e seco) de coleta. As análises estatísticas foram realizadas no software PAST 4.0 com distância de bray curtis e 9999 permutações. O método de ordenação o Escalonamento Multidimensional Não Métrico (NMDS) foi elaborado apenas para área para visualizar os resultados da PERMANOVA no programa R, pacote vegan função metaMDS.

\section{RESULTADOS}

Foram coletados 2149 indivíduos da macrofauna edáfica, pertencentes a 16 grupos taxonômicos, distribuídos em cinco grupos funcionais: engenheiros dos ecossistemas, saprófagos, predadores, onívoros e fitófagos; sendo que os predadores reuniram o maior número de táxons (Quadro 1). Em cada grupo funcional houve um táxon predominante dominante, nos Engenheiros dos Ecossistemas (EDE): Formicidae; nos Saprófagos (SAP): Díptera e Julida; nos Predadores (PRE): Araneae; nos Onívoros (ONI): Coleoptera; e nos Fitófagos (FIT): Hemíptera e Vespidae.

Quadro 1: Presença $(P)$ de grupos funcionais (engenheiros dos ecossistemas, saprófagos, predadores, onívoros e fitófagos) da macrofauna edáfica nos períodos chuvoso (Chu) e seco (Sec) nos ambientes: cerradão (CER), mata dos cocais (MDC), corte e queima (CEQ), eucalipto (EUC) e pastagem (PAS).

\begin{tabular}{|c|c|c|c|c|c|c|c|c|c|c|}
\hline \multirow{2}{*}{$\begin{array}{l}\text { GRUPOS } \\
\text { TAXONÔMICOS }\end{array}$} & \multicolumn{2}{|l|}{ CER } & \multicolumn{2}{|l|}{ MDC } & \multicolumn{2}{|l|}{ CEQ } & \multicolumn{2}{|l|}{ EUC } & \multicolumn{2}{|l|}{ PAS } \\
\hline & Chu & Sec & Chu & Sec & Chu & Sec & Chu & Sec & Chu & Sec \\
\hline \multicolumn{11}{|c|}{ ENGENHEIROS DOS ECOSSISTEMAS } \\
\hline $\begin{array}{l}\text { Formicidae } \\
\text { Haplotaxida } \\
\text { Isoptera } \\
\text { Scolopendrida }\end{array}$ & $P$ & $P$ & $\begin{array}{l}P \\
P\end{array}$ & $P$ & $\begin{array}{l}\mathrm{P} \\
\mathrm{P} \\
\mathrm{P}\end{array}$ & $P$ & $\begin{array}{l}P \\
P\end{array}$ & $\begin{array}{l}P \\
P \\
P\end{array}$ & $\begin{array}{l}P \\
P\end{array}$ & $\begin{array}{l}\mathrm{P} \\
\mathrm{P}\end{array}$ \\
\hline \multicolumn{11}{|l|}{ SAPRÓFAGOS } \\
\hline $\begin{array}{l}\text { Blattidae } \\
\text { Díptera } \\
\text { Julida }\end{array}$ & $\begin{array}{l}\mathrm{P} \\
\mathrm{P} \\
\mathrm{P}\end{array}$ & & $\mathrm{P}$ & & $\mathrm{P}$ & $\mathrm{P}$ & $\mathrm{P}$ & $\mathrm{P}$ & $P$ & \\
\hline \multicolumn{11}{|l|}{ PREDADORES } \\
\hline $\begin{array}{l}\text { Araneae } \\
\text { Dermaptera } \\
\text { Mentodea } \\
\text { Polydesmida } \\
\text { Scorpiones }\end{array}$ & $\begin{array}{l}\mathrm{P} \\
\mathrm{P}\end{array}$ & $P$ & $\begin{array}{l}P \\
P \\
P\end{array}$ & $P$ & $\mathrm{P}$ & $\begin{array}{l}P \\
P \\
P\end{array}$ & $\begin{array}{l}\mathrm{P} \\
\mathrm{P}\end{array}$ & $\begin{array}{l}\mathrm{P} \\
\mathrm{P} \\
\mathrm{P}\end{array}$ & $P$ & $\begin{array}{l}P \\
P\end{array}$ \\
\hline \multicolumn{11}{|l|}{ ONÍVOROS } \\
\hline Coleoptera & $\mathrm{P}$ & $\mathrm{P}$ & $\mathrm{P}$ & $\mathrm{P}$ & $\mathrm{P}$ & $\mathrm{P}$ & $\mathrm{P}$ & $\mathrm{P}$ & $\mathrm{P}$ & $\mathrm{P}$ \\
\hline \multicolumn{11}{|l|}{ FITÓFAGOS } \\
\hline Hemíptera & $P$ & $P$ & $P$ & $P$ & $P$ & $P$ & $P$ & $P$ & $P$ & $P$ \\
\hline Orthoptera & $\mathrm{P}$ & $P$ & $\mathrm{P}$ & $\mathrm{P}$ & $P$ & $\mathrm{P}$ & $P$ & $\mathrm{P}$ & $P$ & \\
\hline Vespidae & $\mathrm{P}$ & $\mathrm{P}$ & $\mathrm{P}$ & $\mathrm{P}$ & $P$ & $P$ & $P$ & $\mathrm{P}$ & $\mathrm{P}$ & $P$ \\
\hline
\end{tabular}


Todos os valores de substituição foram maiores que os valores de aninhamento em todos os ambientes e períodos (Figura 1). No período chuvoso tanto para os ambientes Cerrado, Mata dos Cocais, Corte e Queima, e Eucalipto apresentaram valor de substituição maior na Pastagem, e menor valor no Eucalipto (Figura 1a). Enquanto que no período seco, observou-se que o valor de substituição foi superior no Eucalipto e inferior na Pastagem em relação aos ambientes de estudo (Figura 1b). Contudo, ao considerar a combinação dos dois períodos (chuvoso e seco) em relação aos ambientes, observou-se que o valor de substituição foi maior na Pastagem e menor na Mata dos Cocais (Figura 1c).

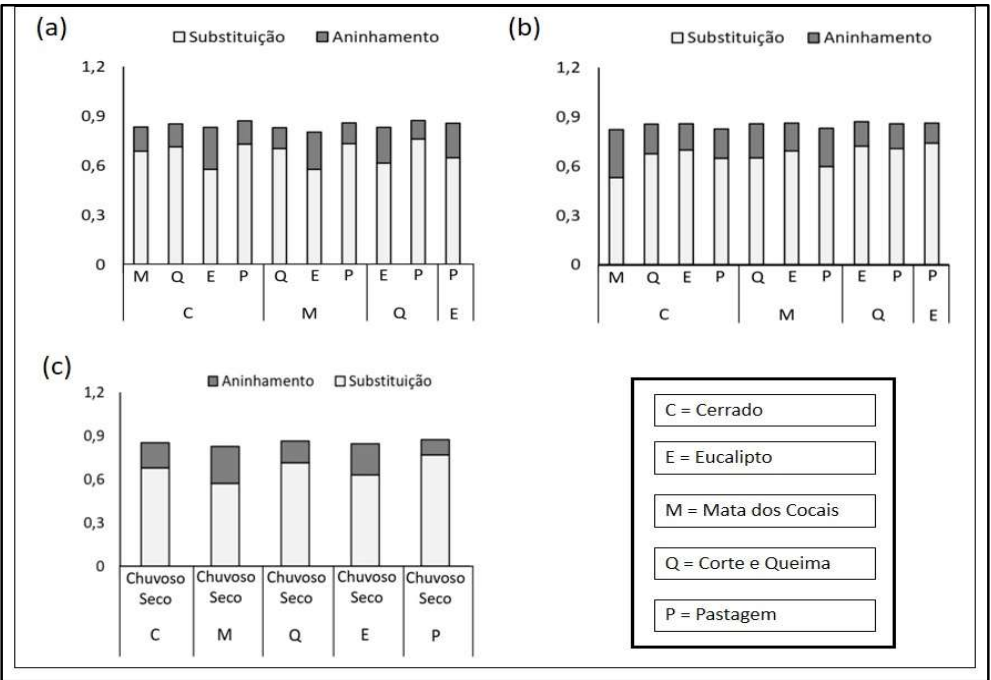

Figura 1: Beta diversidade dos grupos funcionais da macrofauna edáfica, nos ambientes analisados, conforme a sazonalidade: (a) período chuvoso, (b) período seco, (c) período chuvoso e seco.

Com relação a abundância de Engenheiros dos Ecossistemas (EDE), o período seco apresentou mais indivíduos (Tabela 1). Também se observou mais EDE no Eucalipto e na Pastagem que no Cerradão (Tabela 1). Em relação à categoria de referência Mata dos Cocais, o ambiente Corte e Queima apresentou menos abundância de EDE, enquanto que o Eucalipto maior abundância (Tabela 1). Observou-se ainda que a abundância de EDE é maior na Pastagem e Eucalipto, que no Corte e Queima (Tabela 1) e também os EDE são menos abundantes na Pastagem que no Eucalipto (Tabela 1).

Tabela 1: Abundância de engenheiros dos ecossistemas da macrofauna edáfica.

\begin{tabular}{|c|c|c|c|c|}
\hline \multicolumn{5}{|c|}{ Modelo testado: Engenheiros período + ambiente } \\
\hline & Estimador & Erro Padrão & Valor de Z & Valor de $p$ \\
\hline Período Chuvoso & \multicolumn{4}{|c|}{ Categoria de referência } \\
\hline Período Seco & $3,35 \mathrm{E}-01$ & $5,42 \mathrm{E}-02$ & 6,19 & $5,95 \mathrm{E}-10$ \\
\hline Cerradão & \multicolumn{4}{|c|}{ Categoria de referência } \\
\hline Mata dos Cocais & 0,17159 & 0,09526 & 1,801 & 0,071668 \\
\hline Corte e Queima & $-0,10372$ & 0,10193 & $-1,018$ & 0,308902 \\
\hline Eucalipto & 0,88933 & 0,08337 & 10,667 & $2 \mathrm{E}-16$ \\
\hline Pastagem & 0,3287 & 0,09204 & 3,571 & 0,000355 \\
\hline Mata dos Cocais & \multicolumn{4}{|c|}{ Categoria de referência } \\
\hline Corte e Queima & $-0,27531$ & 0,09805 & $-2,808$ & 0,00499 \\
\hline Eucalipto & 0,71774 & 0,07857 & 9,135 & $2 \mathrm{E}-16$ \\
\hline Pastagem & 0,15711 & 0,08772 & 1,791 & 0,07328 \\
\hline Corte e Queima & \multicolumn{4}{|c|}{ Categoria de referência } \\
\hline Eucalipto & 0,99305 & 0,08654 & 11,476 & $2 \mathrm{E}-16$ \\
\hline Pastagem & 0,43242 & 0,09492 & 4,556 & 0,00000522 \\
\hline Eucalipto & \multicolumn{4}{|c|}{ Categoria de referência } \\
\hline Pastagem & $-0,56063$ & 0,07463 & $-7,512$ & $5,82 \mathrm{E}-14$ \\
\hline
\end{tabular}

* Valores em negrito possuem diferença estatística com a categoria de referência. 
A abundância de organismos onívoros foi menor no período seco que no chuvoso (Tabela 2). Observou-se mais onívoros no Eucalipto e no Pastagem que no Cerrado (Tabela 2). A abundância de onívoros também foi superior no Eucalipto em relação à Mata dos Cocais e ao ambiente Corte e Queima (Tabela 2).

Tabela 2: Abundância de onívoros da macrofauna edáfica.

\begin{tabular}{|c|c|c|c|c|}
\hline \multicolumn{5}{|c|}{ Modelo testado: Onívoros período + área } \\
\hline & Estimador & Erro Padrão & Valor de Z & Valor de $p$ \\
\hline Período Chuvoso & \multicolumn{4}{|c|}{ Categoria de referência } \\
\hline Período Seco & $-1,1842$ & 0,3467 & $-3,415$ & 0,000637 \\
\hline Cerradão & \multicolumn{4}{|c|}{ Categoria de referência } \\
\hline Mata dos Cocais & 1,0583 & 0,5985 & 1,768 & 0,077044 \\
\hline Corte e Queima & 0,8878 & 0,6047 & 1,468 & 0,142046 \\
\hline Eucalipto & 2,0559 & 0,5767 & 3,565 & 0,000364 \\
\hline Pastagem & 1,2949 & 0,5914 & 2,189 & 0,028563 \\
\hline Mata dos Cocais & \multicolumn{4}{|c|}{ Categoria de referência } \\
\hline Corte e Queima & $-0,1705$ & 0,5412 & $-0,315$ & 0,752728 \\
\hline Eucalipto & 0,9976 & 0,5089 & 1,961 & 0,049934 \\
\hline Pastagem & 0,2367 & 0,5261 & 0,45 & 0,652804 \\
\hline Corte e Queima & \multicolumn{4}{|c|}{ Categoria de referência } \\
\hline Eucalipto & 1,1681 & 0,5163 & 2,262 & 0,023667 \\
\hline Pastagem & 0,4072 & 0,5332 & 0,764 & 0,445081 \\
\hline Eucalipto & \multicolumn{4}{|c|}{ Categoria de referência } \\
\hline Pastagem & $-0,761$ & 0,5001 & $-1,522$ & 0,12812 \\
\hline
\end{tabular}

* Valores em negrito possuem diferença estatística com a categoria de referência.

A abundância de fitófagos foi menor na Pastagem que no Eucalipto (Tabela 3). Já em relação à sazonalidade, a abundância de organismos fitófagos (Tabela 3), saprófagos (Tabela 4), predadores (Tabela 5), e também a riqueza (Tabela 6) apresentou período chuvoso foi superior ao período seco.

Tabela 3: Abundância de fitófagos da macrofauna edáfica.

\begin{tabular}{|c|c|c|c|c|}
\hline \multicolumn{5}{|c|}{ Modelo testado: Fitófagos período + área } \\
\hline & Estimador & Erro Padrão & Valor de Z & Valor de $p$ \\
\hline Período Chuvoso & \multicolumn{4}{|c|}{ Categoria de referência } \\
\hline Período Seco & $-1,17562$ & 0,30048 & $-3,912$ & 0,0000914 \\
\hline Cerradão & \multicolumn{4}{|c|}{ Categoria de referência } \\
\hline Mata dos Cocais & $-0,09825$ & 0,47602 & $-0,206$ & 0,8365 \\
\hline Corte e Queima & $-0,04869$ & 0,47399 & $-0,103$ & 0,9182 \\
\hline Eucalipto & 0,78222 & 0,45015 & 1,738 & 0,0823 \\
\hline Pastagem & $-0,15743$ & 0,47855 & $-0,329$ & 0,7422 \\
\hline Mata dos Cocais & \multicolumn{4}{|c|}{ Categoria de referência } \\
\hline Corte e Queima & 0,04956 & 0,47791 & 0,104 & 0,9174 \\
\hline Eucalipto & 0,88047 & 0,45434 & 1,938 & 0,0526 \\
\hline Pastagem & $-0,05918$ & 0,48243 & $-0,123$ & 0,9024 \\
\hline Corte e Queima & \multicolumn{4}{|c|}{ Categoria de referência } \\
\hline Eucalipto & 0,83091 & 0,45219 & 1,838 & 0,0661 \\
\hline Pastagem & $-0,10874$ & 0,48043 & $-0,226$ & 0,8209 \\
\hline Eucalipto & \multicolumn{4}{|c|}{ Categoria de referência } \\
\hline Pastagem & $-0,9397$ & 0,457 & $-2,056$ & 0,03978 \\
\hline
\end{tabular}

* Valores em negrito possuem diferença estatística com a categoria de referência.

Tabela 4: Abundância de saprófagos da macrofauna edáfica.

\begin{tabular}{lllll}
\hline \multicolumn{1}{l}{ Modelo testado: Saprófagos $~$} & $\begin{array}{c}\text { período }+ \text { ambiente } \\
\text { Estimador }\end{array}$ & Erro Padrão & Valor de Z & Valor de $\mathbf{p}$ \\
\hline Período Chuvoso & \multicolumn{1}{l}{ Categoria de referência } & & \\
Período Seco & $-1,90 \mathrm{E}+00$ & $6,19 \mathrm{E}-01$ & $-3,06$ & $\mathbf{0 0 2 1 8}$ \\
\hline Cerradão & Categoria de referência & & 0,7394 \\
\hline Mata dos Cocais & 0,2231 & 0,6708 & 0,333 & 0,25767 \\
Corte e Queima & 0,6931 & 0,6124 & 1,132 & 1 \\
Eucalipto & $3,18 \mathrm{E}-14$ & 0,7071 & 0 & 0,42349 \\
Pastagem & $-0,6931$ & 0,866 & $-0,8$ & \\
\hline
\end{tabular}




\begin{tabular}{|c|c|c|c|c|}
\hline Mata dos Cocais & \multicolumn{4}{|c|}{ Categoria de referência } \\
\hline Corte e Queima & 0,47 & 0,5701 & 0,824 & 0,40969 \\
\hline Eucalipto & $-0,2231$ & 0,6708 & $-0,333$ & 0,7394 \\
\hline Pastagem & $-0,9163$ & 0,8367 & $-1,095$ & 0,27344 \\
\hline Corte e Queima & \multicolumn{4}{|c|}{ Categoria de referência } \\
\hline Eucalipto & $-0,6931$ & 0,6124 & $-1,132$ & 0,25767 \\
\hline Pastagem & $-1,3863$ & 0,7906 & $-1,754$ & 0,07951 \\
\hline Eucalipto & \multicolumn{4}{|c|}{ Categoria de referência } \\
\hline Pastagem & $-0,6931$ & 0,866 & $-0,8$ & 0,42349 \\
\hline
\end{tabular}

* Valores em negrito possuem diferença estatística com a categoria de referência.

Tabela 5: Abundância de predadores da macrofauna edáfica.

\begin{tabular}{|c|c|c|c|c|}
\hline \multicolumn{5}{|c|}{ Modelo testado: Predadores período + área } \\
\hline & Estimador & Erro Padrão & Valor de Z & Valor de $p$ \\
\hline Período Chuvoso & \multicolumn{4}{|c|}{ Categoria de referência } \\
\hline Período Seco & $-0,522$ & 0,2618 & $-1,994$ & 0,0462 \\
\hline Cerradão & \multicolumn{4}{|c|}{ Categoria de referência } \\
\hline Mata dos Cocais & 0,7701 & 0,4151 & 1,855 & 0,0636 \\
\hline Corte e Queima & 0,3345 & 0,4211 & 0,794 & 0,4271 \\
\hline Eucalipto & 0,3699 & 0,4206 & 0,879 & 0,3791 \\
\hline Pastagem & 0,4216 & 0,4197 & 1,005 & 0,3151 \\
\hline Mata dos Cocais & \multicolumn{4}{|c|}{ Categoria de referência } \\
\hline Corte e Queima & $-0,4356$ & 0,4083 & $-1,067$ & 0,2860 \\
\hline Eucalipto & $-0,4002$ & 0,4077 & $-0,982$ & 0,3263 \\
\hline Pastagem & $-0,3484$ & 0,4068 & $-0,856$ & 0,3917 \\
\hline Corte e Queima & \multicolumn{4}{|c|}{ Categoria de referência } \\
\hline Eucalipto & 0,0354 & 0,41379 & 0,086 & 0,931817 \\
\hline Pastagem & 0,08716 & 0,41295 & 0,211 & 0,832838 \\
\hline Eucalipto & \multicolumn{4}{|c|}{ Categoria de referência } \\
\hline Pastagem & 0,05176 & 0,41235 & 0,126 & 0,900118 \\
\hline
\end{tabular}

* Valores em negrito possuem diferença estatística com a categoria de referência.

Tabela 6: Riqueza dos grupos funcionais (engenheiros dos ecossistemas, saprófagos, predadores, onívoros e fitófagos) da macrofauna edáfica.

\begin{tabular}{|c|c|c|c|c|}
\hline \multicolumn{5}{|c|}{ Modelo testado: Riqueza período + área } \\
\hline & Estimador & Erro Padrão & Valor de Z & Valor de $p$ \\
\hline Período Chuvoso & \multicolumn{4}{|c|}{ Categoria de referência } \\
\hline Período Seco & $-2,76 \mathrm{E}-01$ & $1,08 \mathrm{E}-01$ & $-2,56$ & 0,01 \\
\hline Cerradão & \multicolumn{4}{|c|}{ Categoria de referência } \\
\hline Mata dos Cocais & 0,07411 & 0,17225 & 0,43 & 0,6670 \\
\hline Corte e Queima & 0,11607 & 0,17054 & 0,681 & 0,4961 \\
\hline Eucalipto & 0,20764 & 0,16699 & 1,243 & 0,2137 \\
\hline Pastagem & $-0,04725$ & 0,17752 & $-0,266$ & 0,7901 \\
\hline Mata dos Cocais & \multicolumn{4}{|c|}{ Categoria de referência } \\
\hline Corte e Queima & 0,04196 & 0,16728 & 0,251 & 0,8019 \\
\hline Eucalipto & 0,13353 & 0,16366 & 0,816 & 0,4146 \\
\hline Pastagem & $-0,12136$ & 0,1744 & $-0,696$ & 0,4865 \\
\hline Corte e Queima & \multicolumn{4}{|c|}{ Categoria de referência } \\
\hline Eucalipto & 0,09157 & 0,16186 & 0,566 & 0,5716 \\
\hline Pastagem & $-0,16333$ & 0,17271 & $-0,946$ & 0,3443 \\
\hline Eucalipto & \multicolumn{4}{|c|}{ Categoria de referência } \\
\hline Pastagem & $-0,25489$ & 0,1692 & $-1,506$ & 0,132 \\
\hline
\end{tabular}

* Valores em negrito possuem diferença estatística com a categoria de referência.

O teste da PERMANOVA indicou alterações significativas na composição dos grupos funcionais (engenheiros dos ecossistemas, saprófagos, predadores, onívoros e fitófagos) da macrofauna edáfica (Tabela 8) para a interação dos fatores: período sazonal (chuvoso e seco) e ambiente (cerradão, mata dos cocais, corte e queima, eucalipto e pastagem). 
Tabela 8: Resultado da PERMANOVA de dois fatores (biótico período * ambiente) referente a composição dos grupos funcionais da macrofauna edáfica.

\begin{tabular}{|c|c|c|c|c|c|}
\hline Source & Soma dos Quadrados & Graus de liberdade & Média dos quadrados & Valor de F & Valor de $p$ \\
\hline Período & 0,68186 & 1 & 0,68186 & 2,9497 & 0,0095 \\
\hline Ambiente & 1,8004 & 4 & 0,45009 & 1,9471 & 0,0058 \\
\hline Interação & 2,2644 & 4 & 0,56609 & 2,4489 & 0,0005 \\
\hline Resíduos & 32,362 & 140 & 0,23116 & & \\
\hline Total & 37,109 & 149 & & & \\
\hline
\end{tabular}

* Valores em negrito possuem diferença estatística com a categoria de referência.

A análise PERMANOVA para a matriz da composição de grupos funcionais mostrou diferenças significativas entre períodos (chuvoso e seco) e ambientes (CER: cerradão; MDC: mata dos cocais; CEQ: corte e queima; EUC: eucalipto e PAS: pastagem). As comparações pairwise indicou diferenças significativas (Tabela 9) entre Chuvoso-Chuvoso (MDC-EUC e CEQ-PAS), entre Chuvoso-Seco (CER-EUC; MDC-EUC; CEQ-CEQ e EUCEUC) com todos os ambientes, exceto EUC-PAS; e PAS com todos os ambientes, exceto PAS-MDC e PAS-CEQ), e entre Seco-Seco (CER-CEQ; CER-EUC; MDC-EUC; CEQ-EUC; CEQ-PAS e EUC-PAS).

Tabela 9: Comparação PERMANOVA pairwise da composição dos grupos funcionais entre diferentes períodos (chuvoso e seco) e ambientes (CER: cerradão; MDC: mata dos cocais; CEQ: corte e queima; EUC: eucalipto; e PAS: pastagem).

\begin{tabular}{|c|c|c|c|c|c|c|c|c|c|c|c|}
\hline & & \multicolumn{5}{|c|}{ Chuvoso } & \multicolumn{5}{|l|}{ Seco } \\
\hline & & CER & MDC & CEQ & EUC & PAS & CER & MDC & CEQ & EUC & PAS \\
\hline \multirow{5}{*}{ Chuvoso } & CER & & 0,4706 & 0,3935 & 0,3073 & 0,1002 & 0,0709 & 0,2517 & 0,2193 & 0,0004 & 0,1566 \\
\hline & MDC & & & 0,2156 & 0,0434 & 0,1826 & 0,0539 & 0,1043 & 0,8079 & 0,0023 & 0,0742 \\
\hline & CEQ & & & & 0,3075 & 0,0263 & 0,2552 & 0,0877 & 0,0164 & 0,0098 & 0,6944 \\
\hline & EUC & & & & & 0,0675 & 0,0183 & 0,0289 & 0,0076 & 0,0253 & 0,1234 \\
\hline & PAS & & & & & & 0,0007 & 0,1079 & 0,3452 & 0,0081 & 0,002 \\
\hline \multirow{5}{*}{ Seco } & CER & & & & & & & 0,333 & 0,0118 & 0,0045 & 0,7543 \\
\hline & MDC & & & & & & & & 0,0591 & 0,0031 & 0,2454 \\
\hline & CEQ & & & & & & & & & 0,0005 & 0,007 \\
\hline & EUC & & & & & & & & & & 0,0214 \\
\hline & PAS & & & & & & & & & & \\
\hline
\end{tabular}

No período chuvoso foi verificado sobreposição da MDC e PAST em relação aos outros ambientes (CER, CEQ e EUC), sendo semelhantes entre si no que se refere a abundância de EDE e ONI (Figura 2 a). Já no período seco houve uma sobreposição dos ambientes CER, PAS e EUC, onde os EDE e os PRE foram abundantes nesses ambientes (Figura 2b). SAP e FIT não foram abundantes em nenhum ambiente dos períodos (chuvoso e seco) analisados (Figura 2).

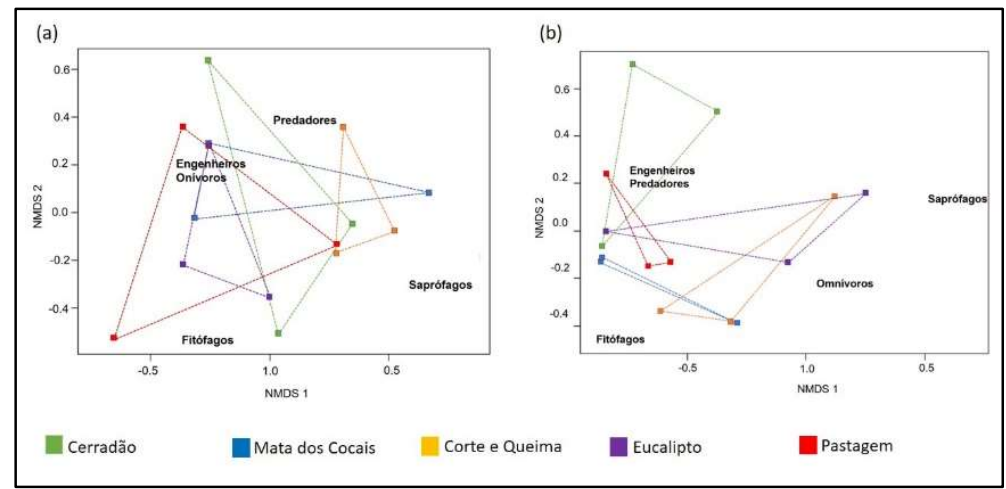

Figura 2: Escalonamento multidimensional não-métrico (NMDS) dos grupos funcionais da macrofauna edáfica em diferentes ambientes no bioma Cerrado: (a) período chuvoso e (b) período seco. 


\section{DISCUSSÃO}

Os engenheiros dos ecossistemas são considerados a guilda mais analisada da macrofauna edáfica por ser representada por uma diversidade de organismos edáficos (BRUSSAARD et al., 2007). Na presente pesquisa, foram encontrados quatro grupos táxons que representam esse grupo: Formicidae, Haplotaxida, Isoptera e Scolopendrida. Dentre estes, Formicidae foi o táxon dominante (Quadro 1).

As formigas foram encontradas em todos os ambientes, tanto no período chuvoso como no período seco (Quadro 1). Tal comportamento, se aplica em razão de, apresentar locomobilidade entre habitats e se condicionarem as alterações sazonais. E por manifestar-se como grupo dominante dos engenheiros dos ecossistemas, deve-se ao fato de ser um táxon com elevada diversidade de espécies que se adaptam facilmente, tanto em ambientes naturais como em ambientes antrópicos.

As formigas exerceram funções importantes nos ambientes de estudo (CER, MDC, CEQ, EUC e PAS). Contribuíram para melhoria das propriedades físicas, químicas e biológicas do solo. Elevaram as condições de aeração, drenagem e porosidade do solo, melhorando a infiltrando de água e redistribuindo matéria orgânica e nutrientes como nitrogênio, carbono e fósforo, além de reduzir ou aumentar a atividade microbiana ao solo (MUELLER et al., 2011; OFFENBERG, 2015; MENANDRO et al., 2019). Segundo Karungi et al. (2018) as formigas também atuam como ferramenta de gestão ambiental, monitorando a biota dos ecossistemas terrestres.

Zhang et al. (2018) desenvolveram uma pesquisa em Luisiana, Estados Unidos da América (EUA) com intuito de entender como os ninhos de formigas alteram as características moleculares do Carbono Orgânico do Solo (COS). Assim, observaram que os formicídeos são importantes engenheiros dos ecossistemas, pois sua colonização alterou significativamente a composição do COS, influenciado pelo aumento de compostos contendo nitrogênio e pela exaustão quase total de compostos de lignina, polissacarídeos e fenol. Também se verificou como as formigas são fundamentais para entender o efeito de bioturbação nos ciclos do carbono e do nitrogênio.

Haplotaxida foi o único táxon pertencente aos Engenheiros dos Ecossistemas (EDE) encontrados exclusivamente em ambiente antrópico (Quadro 1). Barreto-García et al. (2018), afirmaram que em áreas perturbadas as minhocas como EDE são consideradas as mais importantes, pois são encontradas em ambos os estratos de amostragem, favorecendo a redução da compactação do solo. Nesse sentido, Uvarov et al. (2019) referiram-se as minhocas como um grupo-chave de organismos por atuar na estrutura do perfil do solo, nas transformações da matéria orgânica e na rotatividade de nutrientes. Desse modo, a presença desse grupo condicionou a melhoria do teor de matéria orgânica no ambiente de estudo "Corte e Queima".

No grupo Saprófagos, os táxons dominantes foram Díptera e Julida, ambos foram encontrados tanto em ambientes naturais como em ambientes antrópicos (Quadro 1). Quanto à sazonalidade o Díptera foi coletado no período chuvoso e período seco, enquanto o Julida foi exclusivamente no período chuvoso.

Quanto a isso, Bartrons et al. (2018) afirmaram que o Díptera (moscas) aumenta a fertilidade dos solos, melhora a formação pedológica e atuam como catalizadores do crescimento de plantas, alterando a 
estequiometria dessas plantas, em suas fases iniciais de desenvolvimento. Isso ocorre principalmente, devido à presença de Dípteros em uma determinada área influenciar a composição alimentar e a concentração de táxons edáficos específicos. Tais aspectos condicionaram a presença desse táxon em ambientes antrópicos, (Corte e Queima e Eucalipto) e em ambiente natural (Cerradão).

A predominância do grupo Julida, ocorreu preferencialmente nos ambientes naturais Cerradão e Mata dos Cocais (Quadro 1). Lima et al. (2020) explicaram que geralmente esse táxon tem predileção a solo com elevada cobertura de matéria orgânica em decomposição. Além de terem preferência por ambientes escuros e úmidos, que the confere proteção, também facilita sua alimentação, e pela razão de serem saprófagos, consomem plantas caídas e pequenos invertebrados, ambos em decomposição. Desse modo, acredita-se que esse táxon melhorou o perfil do solo dos ambientes em que foram amostrados nessa pesquisa.

Os Predadores foi o grupo funcional de maior número de táxons (Quadro 1), certamente por desempenharem importantes serviços ambientais nos ecossistemas terrestres e desenvolverem uma ampla gama de estratégias de caça e serem facilmente adaptáveis a habitats variados. Nesse grupo funcional, o táxon Araneae foi o dominante, estando presente em todos os ambientes, tanto os naturais como os antrópicos (Quadro 1), provavelmente por ser um grupo de predadores generalistas, que se alimentam de diversos tipos de presas. As aranhas são importantes predadores que participam da manutenção das redes alimentares, geralmente em diferentes ambientes consumem presas de várias cadeias alimentares e viabilizam o transporte de energia na biota do solo (PERKINS et al., 2018; MURPHY et al., 2020).

Ainda no grupo funcional Predadores, observou-se uma particularidade quanto a presença do táxon Scorpiones que ocorreu exclusivamente no período seco em todos os ambientes (Quadro 1), supostamente esse comportamento deve-se ao aumento da disponibilidade de presas, fato também observado por Lira et al. (2013) na estação seca da floresta atlântica brasileira. Os escorpiões como predadores se alimentam de vários tipos de presas que se distribuem em diferentes habitats com ou sem serapilheira, assim podem ocupar distintos níveis tróficos na cadeia alimentar. Alguns habitam a camada superior da serapilheira como por exemplo Tityus pusillus, considerado um predador de emboscada; e outros, do gênero Ananteris têm predominância no fundo da camada de serapilheira, atuando como forrageador ativo (LIRA et al., 2013). Nesse sentido, atendendo a heterogeneidade dos habitas, muitos artrópodes podem ser presas potenciais para os escorpiões no solo, podendo inclusive alterar a composição faunística do ambiente ou propiciar o seu equilíbrio.

O táxon Coleoptera foi amostrado em todos os ambientes, no período chuvoso e no período seco (Quadro 1), provavelmente por ser um táxon altamente adaptável as condições de solo, vegetação e sazonalidade. Representantes desse táxon, os besouros, têm alto potencial de fornecer serviços ecológicos valiosos nos ecossistemas terrestres, consomem invertebrados considerados "pragas" para plantações, e também se nutrem de sementes de plantas daninhas, promovendo o equilíbrio ecológico num dado ambiente (KULKARNI et al., 2017). Nesse contexto, Kulkarni et al. (2017) cita alguns elementos que condicionam a adaptabilidade dos besouros a diferentes ambientes, como a estrutura do dossel das plantas, 
a densidade da vegetação e os fatores abióticos: temperatura, umidade e luminosidade. Esses elementos influenciam tanto na seleção de habitats pelos besouros como na distribuição desse táxon nos diferentes perfis de solo. Chávez-Suárez et al. (2016), afirmam que Coleoptera é um táxon importante, pois participa da trituração de resíduos vegetais, sendo considerado um indicador de acúmulo de biomassa e de matéria orgânica.

No grupo dos Fitógrafos, os taxóns Hemiptera, Orthoptera e Vespidae foram encontrados em todos os ambientes (Quadro 1), isso se aplica, provavelmente, por serem grupos altamente adaptáveis a variação ambiental, além de possuírem mobilidade entre as diferentes áreas, naturais ou antrópicas. Nesse sentido, Andrew et al. (2005) afirmaram que insetos fitófagos são altamente móveis, podendo inclusive migrar rapidamente para outras áreas devido as mudanças climáticas. De modo geral, os insetos fitófagos podem causar impactos na produtividade de culturas vegetais, atuando nos ciclos de nutrientes e desempenhando importantes funções em distintos níveis dos ecossistemas terrestres.

A beta diversidade ( $\beta$ ), segundo Baselga (2012) e Heino et al. (2015) é definida como variação da composição das espécies entre áreas que pode resultar na substituição de certas espécies de uma comunidade para outra, podendo induzir um processo de perda ou ganho de espécies. Nesse sentido, na beta diversidade da macrofauna edáfica, para todos os pares de grupos referentes aos ambientes, os valores de substituição são maiores que os de aninhamento (Figura 2), indicando que os processos que ocorrem no solo, atrelado a sazonalidade, modificam a composição dos grupos funcionais. Essa modificação é resultado não apenas da rotatividade de táxons (substituição), mas também da riqueza desses táxons entre os ambientes (aninhamento). Por isso, que a beta diversidade é um parâmetro-chave para compreender a comunidade ecológica de um determinado ambiente.

Observou-se que houve substituição de grupos taxonômicos nos diferentes períodos (chuvoso e seco) em todos os ambientes de estudo (Figura 1). No período chuvoso, o valor de substituição dos grupos taxonômicos foi maior na Pastagem e menor no Eucalipto em relação a todos ambientes (Figura 1a); enquanto que no período seco Eucalipto apresentou maior valor de substituição dos grupos taxonômicos e Pastagem, valor inferior (Figura 1b). Quando ocorre a combinação dos períodos (chuvoso e seco) a Pastagem ainda apresenta maior substituição de grupos taxonômicos (Figura 1c).

Esses valores podem indicar que a sazonalidade interfere na beta diversidade, precisamente na substituição de grupos taxonômicos. Tal comportamento na Pastagem em período chuvoso pode estar associado ao pastejo rotacionado utilizado nesse ambiente, que consiste em dividir a área da pastagem em piquetes, submetendo-os a períodos alternados de descanso e pastejo. A utilização desse tipo de sistema pode ter favorecido um processo de recolonização de organismos edáficos que consequentemente elevou a substituição de grupos taxonômicos.

Embora o Eucalipto seja uma planta perenifólia, sua área de cultivo é formada de sub-bosque constituído por espécies herbáceas e arbóreas nativas (que ficam abaixo da copa dos eucaliptos) de folhas finas, que têm a tendência de se desprenderem facilmente e ficarem aderidas ao solo, aumentando a serapilheira e acelerando o processo de decomposição; provavelmente por essa razão, tenha ocorrido no 
período seco maior valor de substituição de indivíduos edáficos nesse ambiente.

Jiménez-Valverde et al. (2010) e Carvalho et al. (2011) relacionam a beta diversidade a fatores geográficos ou ambientais, como também a associação entre eles; sendo que dependerá do nível taxonômico pesquisado, da sua distribuição e da região geográfica analisada. Esses aspectos levantados pelos autores corroboram com o que foi observado nessa pesquisa.

Os engenheiros dos ecossistemas foram mais abundantes no período seco (Tabela 1). Acredita-se que o período seco influenciou a permanência desses organismos acelerando suas atividades de construção de estruturas biogênicas para se proteger dos efeitos de elevadas temperaturas do solo, construindo nos ambientes, ninhos em zonas mais profundas.

McAfee et al. (2019) evidenciaram que os engenheiros dos ecossistemas podem propiciar efeitos positivos na biodiversidade, com aumento da disponibilidade de habitats, fornece consequentemente refúgios contra estressores, como temperaturas elevadas, dessecação e predação.

A abundância dos engenheiros dos ecossistemas (Tabela 1) e dos onívoros (Tabela 2) foi maior nos ambientes: 1) Eucalipto e Pastagem em relação ao Cerradão; 2) Eucalipto em relação à Mata dos Cocais; e 3) Eucalipto e Pastagem em relação à Corte e Queima. A maior abundância desses grupos funcionais, no Eucalipto e na Pastagem indica que foram os mais expressivos nesses ambientes, acelerar suas atividades de engenharia e consumo de matéria de origem animal e vegetal, o que pode ter resultado na melhoria desses ambientes que considerados antropizados.

Associado ao fato do Eucalipto ser caracterizado como vegetação florestal, acredita-se que segundo Garleti et al. (2013) os solos habitados por vegetação florestal são mais propensos as condições de desenvolvimento e instalação da macrofauna edáfica, influenciado principalmente pela deposição de serapilheira. Pois na serapilheira é possível encontrar tanto fragmento de folhas e até mesmo pequenos invertebrados que se tornam recursos alimentares para esses grupos (EDE e ONI), que posteriormente estarão adicionando bolotas fecais, melhorando a fertilidade do solo. Nesse sentido, Elie et al. (2018) afirmam que a serapilheira associada a fauna do solo são extremamente importantes para o equilíbrio dos ecossistemas terrestres.

Quanto a Pastagem, pode ter ocorrido acúmulo de biomassa no solo, excedente do período chuvoso, fato também observado por Lima et al. (2020), que provavelmente tenha favorecido a permanência dos EDE e dos ONI nesse ambiente. Geralmente áreas ricas em matéria orgânica, condicionadas pela presença significativa de serapilheira, possuem solos mais porosos que facilitam as atividades dos engenheiros do solo como formigas e cupins - observado nessa pesquisa - que podem instalar seus nichos nessas áreas, melhorando ainda mais a oxigenação do solo, facilitando ainda o transporte de outros nutrientes como fósforo e nitrogênio para as plantas.

Souza et al. (2016) também observaram que os táxons Formicidae e Oligochaeta - pertencentes aos EDE - determinam as propriedades físicas e químicas do solo, principalmente quanto a macroporosidade, densidade e matéria orgânica, concentrando-se ao solo nutrientes, como: cálcio, fósforo e potássio.

A abundância de fitófagos (Tabela 3) no Eucalipto foi superior a Pastagem, por ser um ambiente 
formado por espécie arbórea que fornece sombreamento, além de possuir entre as árvores os sub-bosques, formado predominantemente por plantas herbáceas. Essas características propiciam aos FIT condições de disporem de nutrientes e realizarem suas atividades edáficas, de controle de ervas daninhas, de modo que podem influenciar na estrutura física e química do solo e no perfil da comunidade vegetal.

Para a abundância de organismos onívoros (Tabela 2), fitófagos (Tabela 3), saprófagos (Tabela 4), predadores (Tabela 5), e também a riqueza (Tabela 7) o período chuvoso foi superior ao período seco. Acredita-se que o período chuvoso influenciou a permanência desses organismos nos diferentes ambientes, fazendo com que acelerem suas atividades, de: decomposição de matéria orgânica, controle da população de invertebrados, microrganismos e ervas daninhas. Por fim, esse período favoreceu a disponibilidade de alimento e a umidade do solo, que condicionou a proliferação desses grupos funcionais nos diferentes ambientes, dando origem a novos nichos ecológicos e melhorando a fertilidade do solo.

Ferreira et al. (2019) realizaram uma pesquisa no município de Guaíra (Estado do Paraná), Brasil, e observaram que o período chuvoso foi um fator determinante para permanência de invertebrados edáficos no fragmento nativo da Mata Atlântica. Assim, esses autores afirmaram que a sazonalidade foi um elemento importante na coleta das espécies edáficas, corroborando com Nunes et al. (2019) que observaram que o período chuvoso tem uma tendência de elevar o número de indivíduos edáficos.

No período chuvoso foi verificado sobreposição da Mata dos Cocais e Pastagem em relação aos outros ambientes (Cerradão, Corte e Queima e Eucalipto), sendo semelhantes entre si no que se refere a abundância de engenheiros dos ecossistemas e onívoros (Figura 2a). Sendo assim, o perfil vegetacional dos ambientes no período chuvoso propiciaram qualidade nutricional para os organismos onívoros e para os engenheiros do solo, e de tal forma que favoreceu a proliferação desses indivíduos que se beneficiaram da serapilheira, oriunda da vegetação. Tal comportamento demonstra que esses grupos funcionais atuaram mais expressivamente nesses ambientes, construindo estruturas biogênicas para melhorar a física do solo, e ao mesmo tempo consumindo organismos animais e/ou vegetais, propiciando equilíbrio ecológico e garantindo sua permanência nesses ambientes.

No Cerradão (período seco) observou-se uma leve sobreposição em relação a Pastagem e o Eucalipto, onde os engenheiros dos ecossistemas e os predadores foram abundantes nesses ambientes (Figura 2b). Provavelmente significa que estes ambientes oferecem concentração semelhante de organismos edáficos atuando simultaneamente como engenheiros dos ecossistemas e predadores (Figura 2b) com intuito de construir câmaras biogênicas e regular a população de organismos nesses ambientes. O Cerradão, mesmo com alteração sazonal (chuvoso e seco), por ser um ambiente natural, não alterou a composição de engenheiros dos ecossistemas.

Nesse cenário, tanto a Pastagem e o Eucalipto, incorporam ao solo os resíduos vegetais excedentes do período chuvoso, fornecendo mais nutrientes aos organismos edáficos, esse evento provavelmente propiciou a similaridades com o Cerrado; além disso, as gramíneas (no caso do ambiente Pastagem) possuírem efeitos alelopáticos que inibem populações de fungos, principalmente durante o período seco, fato observado por Peña-Peña et al. (2016) em que na estação seca a deterioração da pastagem foi muito 
lenta, quando comparada à estação chuvosa que teve uma taxa de 5 vezes mais, que não suprimiu a população de fungos.

Noguera-Talavera et al. (2017) observaram no período seco que o táxon Formicidae (engenheiros dos ecossistemas) elevou sua atividade de forrageamento ao solo devido ao desfloramento da vegetação; além disso, foi constatado, a predação de invertebrados pertencentes a esse táxon por aranhas (PRE), sendo considerado também pelos autores um mecanismo de regulação populacional.

Observou-se ainda que a adaptação dos engenheiros do solo que não ficou condicionada a nenhum tipo de sazonalidade, mas pelo contrário, esse grupo funcional foi encontrado em abundância tanto no período chuvoso (Figura 2a) como no período seco (Figura 2b), e em ambientes naturais e antrópicos, cujos os recursos vegetais não foram escassos, favorecendo o exercício de suas atividades para a melhoria da estrutura de cada ambiente. Segundo Silva et al. (2016) a estrutura do solo é menos afetada quando a cobertura vegetal é mantida semelhante, o que pode também ter favorecido a proliferação dos engenheiros nesses ambientes.

\section{CONCLUSÕES}

O grupo funcional da macrofauna edáfica que agrega mais táxons, é o dos predadores, tendo sua importância na regulação população de invertebrados que habitam áreas de formação vegetacional florestada e também de áreas que originalmente apresentavam essa característica, mas que sofreram progressivamente perturbações antrópicas.

Os engenheiros dos ecossistemas é o grupo mais adaptável a ambientes naturais (Cerradão e Mata dos Cocais) e antrópicos (Corte e Queima, Eucalipto e Pastagem), influenciado principalmente pelas características vegetacionais e edáficas de cada ambiente, que imobilizam a escassez de recursos nutricionais, fazendo com que esse grupo funcional persista as variações sazonais (chuvoso e seco).

De modo geral, os grupos funcionais da macrofauna edáfica (engenheiros dos ecossistemas, saprófagos, predadores, onívoros, fitófagos) desempenham atividades que regulam diversos processos físicos, químico e biológicos que ocorrem no solo do bioma Cerrado, além de promover o seu equilíbrio e o funcionamento habitual.

AGRADECIMENTOS: a Coordenação de Aperfeiçoamento de Pessoal de Nível Superior, CAPES, Brasil, pela bolsa de doutorado.

\section{REFERÊNCIAS}

ANDREW, N. R.; HUGHES, L.. Diversity and assemblage structure of phytophagous Hemiptera along a latitudinal gradient: predicting the potential impacts of climate change. Global Ecology and Biogeography, v.14, p.249-262, 2005. DOI: $\underline{\text { http://dx.doi.org/10.1111/j.1466-822x.2005.00149.x }}$

BARRETO-GARCÍA, O. A.; GUEVARA-GUTIÉRREZ, R. D.; OLGUÍN-LÓPEZ, J. L.; ANCILLA-VILLA, O. R.; VALDOVINOS, E. K. M.; HERNÁNDEZ, J. E. M.. Macroinvertebrados de hojarasca y suelo em selva baja caducifólia y zonas perturbadas. Idesia, v.36, n.1, p.105-113, 2018. DOI: http://dx.doi.org/10.4067/S0718-34292018000100105

BARTRONS, M.; SARDANS, J.; HOEKMAN, D.; PENUELAS, J.. Trophic transfer from aquatic to terrestrial ecosystems: a test of the biogeochemical niche hypothesis. Ecosphere, v.9, n.7, p.1-13, 2018. DOI: https://doi.org/10.1002/ecs2.2338 
BASELGA, A.. The relationship between species replacement, dissimilarity derived from nestedness, and nestedness.

Global Ecology and Biogeography, v.21, p.1223-1232, 2012. DOI: http://doi.org/10.1111/j.1466-8238.2011.00756.x

BRUSSAARD, L.; RUITER, P. C.; BROWN, G. G.. Soil biodiversity for agricultural sustainability. Agriculture, Ecosystems and Environment, v.121, p.233-244, 2007. DOI: https://doi.org/10.1016/j.agee.2006.12.013

BROWN, G. G.; FRAGOSO, C.; BAROIS, I.; ROJAS, P.; PATRÓN, J. C.; BUENO, J.; MORENO, A. G.; LAVELLE, P.; ORDAZ, V.; RODRÍGUEZ, C.. Diversidad y rol funcional de la macrofauna edáfica en los ecosistemas tropicales mexicanos. Acta Zoológica Mexicana, número especial 1, p.79-110, 2001. DOI: https://doi.org/10.21829/azm.2001.8401847

CARVALHO, J. C.; CARDOSO, P.; CRESPO, L. C.; HENRIQUES, S.; CARVALHO, R.; GOMEZ, P.. Determinants of beta diversity of spider in coastal dunes along a gradient of mediterraneity. Diversity and Distributions, v.17, p.225-234, 2011. DOI: https://doi.org/10.1111/i.1472-4642.2010.00731.x

CHÁVEZ-SUÁREZ, L.; LABRADA-HERNÁNDEZ, Y.; ÁLVAREZFONSECA, A.. Macrofauna del suelo em ecosistemas ganaderos de montaña en Guisa, Granma, Cuba. Pastos y Forrajes, v.39, n.3, p.111-115, 2016.

ELIEA, F.; VINCENOTA, L.; BERTHEB, T.; QUIBELA, E.; ZELLERC, B.; SAINT-ANDRÉC, L.; NORMANDA, M.; CHAUVATA, M.; AUBERT, M.. Soil fauna as bioindicators of organic matter export in temperate forests. Forest Ecology and Management, v.429, p.549-557, 2018. DOI: https://doi.org/10.1016/j.foreco.2018.07.053

FERREIRA, C. R.; GUEDES, J. N.; ROSSET, J. S.; ANJOS, L. H. C.; PEREIRA, M. G.. Diversity of the edaphic macrofauna in areas managed under notillage for different periods. Semina: Ciências Agrárias, v.40, n.2, p.599-610, 2019. DOI: https://doi.org/10.5433/1679-0359.2019v40n2p599

FROUZ, J.. Effects of soil macro and mesofauna on litter decomposition and soil organic matter stabilization.

Geoderma, v.332, p.161-172, 2017. DOI:

http://dx.doi.org/10.1016/j.geoderma.2017.08.039

GARLET, J.; COSTA, E. C.; BOSCARDIN, J.. Caracterização da fauna edáfica em plantios de Eucalyptus spp. Ciência Florestal, v.23, n.3, p.337-344, 2013. DOI: http://dx.doi.org/10.5902/1980509810545

JIMÉNEZ-VALVERDE, A.; BASELGA, A.; MELIC, A.; TXASKO, N.. Climate and regional beta-diversity gradients in spiders: dispersal capacity has nothing to say?. Insect Conservation and Diversity, n.3, p.51-60, 2010. DOI:

https://doi.org/10.1111/j.1365-2311.2006.00848.x

KULKARNIA, S. S.; DOSDALLA, L. M.; SPENCEB, J. R.; WILLENBORGC, C. J.. Field density and distribution of weeds are associated with spatial dynamics of omnivorous ground beetles (Coleoptera: Carabidae). Agriculture, Ecosystems and Environment, v.236, p.134-141, 2017. DOI: http://dx.doi.org/10.1016/j.agee.2016.11.018

LIMA, C. S.; DALZOCHIO, M. S.; SILVA, E. F.; PÉRICO, E.. Macrofauna edáfica e sua relação com sazonalidade em sistema de uso do solo, bioma cerrado. Revista Ibero
Americana de Ciências Ambientais, v.11, n.2, p.1-13, 2020. DOI: http://doi.org/10.6008/CBPC2179-6858.2020.002.0001

LIRA, A. F. A.; DESOUZA, A. M.; SILVA FILHO, A. A. C.; ALBUQUERQUE, C. M. R.. Spatiotemporal microhabitat use by two co-occurring species of scorpions in Atlantic rainforest in Brazil. Zoology, v.116, n.3, p.182-185, 2013. DOI: https://doi.org/10.1016/j.zool.2018.06.001

MCAFEE, D.; BISHOP, M. J.. The mechanisms by which oysters facilitate invertebrates vary across environmental gradients. Oecologia, v.189, p.1095-1106, 2019. DOI: https://doi.org/10.1007/s00442-019-04359-3

MENANDRO, L. M. S.; MORAES, L. O.; BORGES, C. D.; CHERUBIN, M. R.; CASTIONI, G. A.; CARVALHO, J. L. N. Soil macrofauna responses to sugarcane straw removal for bioenergy production. BioEnergy Research, v.12, p.944-957, 2019. DOI: https://doi.org/10.1007/s12155-019-10053-2

MUELLER, U. G.; MIKHEYEV, A. S.; HONG, E.; SEN, R.; WARREN, D. L.; SOLOMON, S. E.; ISHAK, H. D.; COOPER, M.; MILLER, J. L.; SHAFFER, K. A.; JUENGER, T. E.. Evolution of col-tolerant fungal symbionts permits winter fungiculture by leafcutter ants at the northern frontier of a tropical antfungus symbiosis. Proceedings of the National Academy of Sciences of the United States of America, v.108, p.40534056, 2011. DOI: https://doi.org/10.1073/pnas.1015806108

MURPHY, S. M.; LEWIS, D.; WIMP, G. M.. Predator population size structure alters consumption of prey from epigeic and grazing food webs. Oecologia, v.192, p.791-799, 2020. DOI: https://doi.org/10.1007/s00442-020-04619-7

NOGUERA-TALAVERA, A.; REYES-SÁNCHEZ, N.; MENDIETAARAICA, B.; SALGADO-DUARTE, M. M.. Soil macrofauna as indicator of agroecological conversion of a productive system of Moringa oleifera Lam. in Nicaragua. Pastos y Forrajes, v.40, n.4, p.249-258, 2017.

NUNES, L. A. P. L.; ARAÚJO, A. S. F.; PESSOA, M. M. C.; SOUSA, R. S.; SILVA, J. D. C.; MATOS-FILHO, C. H. A.. Edaphic fauna in a vegetation gradient in the Sete Cidades National Park. Brazilian Journal of Biology, v.79, n.1, p.45-51, 2019. DOI: https://doi.org/10.1590/1519-6984.174135

OFFENBERG, J.. Review: Ants as tools in sustainable agriculture. Journal of Applied Ecology, v.52, p.1197-1205, 2015. DOI: https://doi.org/10.1111/1365-2664.12496

PEÑA-PEÑA, K.; IRMLER, U.. Moisture seasonality, soil fauna, litter quality and land use as drivers of decomposition in Cerrado soils in SE-Mato Grosso, Brazil. Applied Soil Ecology, v.107, p.124-133, 2016. DOI:

http://dx.doi.org/10.1016/j.apsoil.2016.05.007

PERKINS, M. J.; INGER, R.; BEARHOP, S.; SANDERS, D.. Multichannel feeding by spider functional groups is driven by feeding strategies and resource availability. Oikos, v.127, p.23-33, 2018. DOI: https://doiorg.ez316.periodicos.capes.gov.br/10.1111/oik.04500

RAFAEL, J. A.. Insetos do Brasil: Diversidade e Taxonomia. Ribeirão Preto: Holos, 2012.

SILVA, M. S. C.; CORREIA, M. E. F.; SILVA, E. M. R.; MADDOCK, J. E. L.; PEREIRA, M. G.; SILVA, C. F.. Soil Fauna 
Communities and Soil Attributes in the Agroforests of Paraty. Floresta e Ambiente, v.23, n.2, p.180-190, 2016. DOI: http://dx.doi.org/10.1590/2179-8087.059813

SWIFT, M. J.; BIGNELL, D.; MOREIRA, F. M. S.; HUISING, J.. O inventário da biodiversidade biológica do solo: conceitos e orientações gerais. In: MOREIRA, F. M. S.; HUISING, E. J.; BIGNELL, D. E.. Manual de biologia dos solos tropicais: amostragem e caracterização da biodiversidade. Lavras: UFLA, 2010. p.23-41.
UVAROV, A. V.; ILIEVA-MAKULEC, K.; KARABAN, K.;

YAKOVENKO, N. S.; UCHMAŃSKI, J.. Effects of Intra- and Interspecific Interactions in Earthworm Assemblages: A Comparative Study. Biology Bulletin, v.46, n.5, p.475-482, 2019. DOI: https://doi.org/10.1134/S106235901905011X

ZHANG, Z.; WEI, Z.; WANG, J. J.; XIAO, R.; MENG, Y.; WU, H.; LYU, X.. Ants alter molecular characteristics of soil organic carbon determined by pyrolysis-chromatography/mass spectrometry. Applied Soil Ecology, v.130, p.91-97, 2018. DOI: https://doi.org/10.1016/j.apsoil.2018.05.020

A CBPC - Companhia Brasileira de Produção Científica (CNPJ: 11.221.422/0001-03) detém os direitos materiais desta publicação. Os direitos referem-se à publicação do trabalho em qualquer parte do mundo, incluindo os direitos às renovações, expansões e disseminações da contribuição, bem como outros direitos subsidiários. Todos os trabalhos publicados eletronicamente poderão posteriormente ser publicados em coletâneas impressas sob coordenação da Sustenere Publishing, da Companhia Brasileira de Produção Científica e seus parceiros autorizados. Os (as) autores (as) preservam os direitos autorais, mas não têm permissão para a publicação da contribuição em outro meio, impresso ou digital, em português ou em tradução. 